\title{
Antoine SCHNAPPER, David, la politique et la Révolution
}

Paris, Gallimard, collection Bibliothèque illustrée des histoires

\section{Annie Duprat}

\section{Q OpenEdition}

1 Journals

Édition électronique

URL : https://journals.openedition.org/ahrf/13670

DOI : $10.4000 / a h r f .13670$

ISSN : 1952-403X

Éditeur :

Armand Colin, Société des études robespierristes

Édition imprimée

Date de publication : 1 septembre 2015

Pagination : 266-267

ISBN : 9782200929855

ISSN : 0003-4436

Référence électronique

Annie Duprat, "Antoine Schnapper, David, la politique et la Révolution », Annales historiques de la Révolution française [En ligne], 381 | juillet-septembre 2015, mis en ligne le 08 janvier 2016, consulté le 23 avril 2022. URL : http://journals.openedition.org/ahrf/13670 ; DOI : https://doi.org/10.4000/ahrf. 13670

Ce document a été généré automatiquement le 23 avril 2022.

Tous droits réservés 


\section{Antoine SCHNAPPER, David, la politique et la Révolution}

Paris, Gallimard, collection Bibliothèque illustrée des histoires

\section{Annie Duprat}

\section{RÉFÉRENCE}

Antoine SCHNAPPER, David, la politique et la Révolution, Paris, Gallimard, collection

Bibliothèque illustrée des histoires, 450 p., ISBN 978-2-07-014269-9, 39,90€.

1 Pascal Griener, historien de l'art spécialiste du XVIII ${ }^{\mathrm{e}}$ siècle européen, a entrepris de reprendre les notices de catalogues d'exposition et les articles consacrés à David par Antoine Schnapper afin de leur redonner du lustre et l'importance scientifique qu'ils méritaient d'avoir. En effet, dans une belle préface, Pascal Griener rappelle qu'à l'occasion de la grande exposition du Louvre consacrée à David en 1989, Schnapper avait dirigé un épais catalogue et participé, en 1991, au colloque David contre David dont la publication en deux volumes (1993) à la Documentation française a marqué non seulement l'état des recherches sur l'histoire de ce peintre, mais aussi la mise au grand jour d'un clivage profond entre les historiens de l'art. En effet, Régis Michel, l'un des commissaires de l'exposition du Louvre et co-organisateur du colloque qui a suivi, développe une théorie radicale sur un nécessaire aggiornamento de la discipline. Il en prône une approche plus conceptuelle, enrichie des apports de la sociologie, et considère Antoine Schnapper comme une figure du passé. Pour marquer son coup d'éclat, Régis Michel, qui a choisi le titre du colloque David contre David justement pour opposer deux façons différentes de faire de l'histoire de l'art, singulièrement en ce qui concerne le peintre des Sabines, signe son introduction, véritable réquisitoire contre la vieille Sorbonne, « Régis Michel, non-historien d'art ». Les polémiques qui ont suivi ont été rudes, mais également fructueuses. Près de trente années plus tard, la publication du présent ouvrage, livre d'hommage et, davantage encore, livre scientifique de haute tenue, fait le point sur un clivage qui apparaît beaucoup moins nettement aujourd'hui. 
Dans sa préface, dont on recommandera la lecture à tous ceux qui souhaitent connaître l'historiographie et les enjeux de cette question, Pascal Griener revient sur le rôle d'André Chastel et d'Antoine Schnapper dans la préfiguration d'un Institut national d'histoire de l'art (INHA). André Chastel, décédé en 1990, ne verra pas l'ouverture de l'INHA en 2001. Quant à Antoine Schnapper, frappé par la maladie, il décède prématurément en 2004.

2 Le choix des textes qui a été opéré ici permet d'illustrer un moment essentiel, non seulement dans l'histoire de l'art mais aussi dans l'histoire de la Révolution française. Le contexte historico-politique et la recherche archivistique la plus pointue permettent de comprendre comment a travaillé un artiste rapidement devenu le chef de file du néo-classicisme, chef d'une école qui pense la peinture comme un moyen d'intervenir sur la chose publique, citoyen engagé et très actif durant toute la décennie révolutionnaire et au-delà, mais selon des modalités différentes. Car une question demeure : David se rallie-t-il pleinement à Napoléon ou demeure-t-il, en secret un jacobin fidèle jusqu'au bout à ses engagements de 1793 ? Schnapper répond positivement et soutient avec de bons arguments, la permanence des idées révolutionnaires de David. L'argumentation de l'historien réunit un constat : Napoléon a réalisé une bonne partie des demandes de la classe à laquelle appartient David (ordre, droit de propriété, retour de la stabilité politique et de la prospérité). David est fidèle à ses idéaux en ralliant sincèrement Bonaparte, même si les "historiens de gauche", comme les désignait Antoine Schnapper ne pouvaient - ne voulaient? - pas admettre cela.

3 Le livre réunit six textes : 1/une monographie, David témoin de son temps, rédigée à la demande de l'office du livre de Fribourg. Mais les conditions d'édition n'ayant pas été assez scientifiques à son goût, Antoine Schnapper en a livré une version plus courte mais aussi plus scientifique à la revue Commentaires en 1978. C'est cette version qui est à présent reprise ; $2 /$ la notice publiée dans le catalogue De David à Delacroix. La peinture française de 1774 à 1830 (1974), republiée dans la revue Contrepoints en $1975 ; 3 /$ « David et l'argent », communication au colloque David contre David, 1993; 4/«Révolutionnaire avant la Révolution", choix de notices concernant la relation du peintre avec les questions politiques et figurant dans le catalogue de l'exposition de $1989 ; 5 /$ «e premier peintre de la Révolution ", notice extraite du catalogue de l'exposition de $1989 ; 6 /$ / Peindre pour l'Empire », notice extraite du catalogue de l'exposition de 1989. Assorti d'une abondante bibliographie (mais qui n'a pas été mise à jour) et d'une iconographie de bonne qualité (près d'une centaine d'illustrations, en couleurs pour la plupart), ce livre est une ressource intellectuelle de premier ordre sur "le cas David", ainsi qu'un très bel hommage rendu à Antoine Schnapper. Que l'on me permette cependant d'exprimer un regret. Pour l'avoir entendu dans une conférence démontrer avec finesse que David ne pouvait pas être l'auteur des caricatures que le Comité de salut public lui avait commandé - et payé - et suggérer quelques pistes, je regrette que l'on ne trouve aucune trace de la pensée d'Antoine Schnapper sur cette question. Serait-ce parce qu'il n'avait pas souhaité écrire sur un sujet peut-être considéré comme subalterne? 